\title{
Psychometric properties of the Danish versions of Headache-Specific Locus of Control Scale and Headache Management Self-Efficacy Scale
}

\author{
Jacob Sander Hansen · Lars Bendtsen • \\ Rigmor Jensen
}

Received: 5 May 2009/Accepted: 10 July 2009/Published online: 19 August 2009

(C) Springer-Verlag 2009

\begin{abstract}
The purpose of the study is to test the crosscultural adaptation and psychometric properties of a Danish version of the Headache-Specific Locus of Control Scale (HSLC) and the Headache Management Self-Efficacy Scale (HMSE) in a tertiary headache centre. HSLC and HMSE are headache-specific measures of locus of control (LOC) and SE. The Danish versions of the HSLC and the HMSE were created according to the guidelines for cross-cultural adaptation of self-report measures. The HSLC and HMSE were administered to 135 consecutively referred headache patients in a tertiary headache centre together with other self-report measures concerning general distress, anxiety, depression, and health-related quality of life. Internal stability of the HSLC subscales and the HMSE were analysed using Chronbach's $\alpha$ coefficient. The psychometric properties of the Danish version of the HSLC and the HMSE were analysed using Spearman's rank correlation test. Cronbach's $\alpha$ ranged from 0.71 to 0.88 and the corrected item-total correlations were acceptable. The mean corrected item-total correlations for the three subscales of HSLC (health-care LOC, internal LOC, and chance LOC) were $0.40,0.59$, and 0.40 respectively. The mean corrected item-total correlation for HMSE was 0.42 . High HMSE scores were found to be associated with high scores on internal LOC and low scores on chance LOC. High scores on chance LOC were positively associated
\end{abstract}

J. S. Hansen · L. Bendtsen · R. Jensen

Department of Neurology, Danish Headache Centre,

University of Copenhagen, Glostrup Hospital,

Copenhagen, Denmark

J. S. Hansen $(\bowtie)$

Mental Health Centre Glostrup,

Blok C, Nordre Ring 29-67, 2600 Glostrup, Denmark

e-mail: jsha@glo.regionh.dk; j.s.hansen@ privat.dk with low scores on social functioning independently of headache frequency. The results are consistent with the earlier findings of the original American versions of HMSE and HSLC. These scales seem to be valid and valuable tools for testing of psychological aspects related to level of functioning and quality of life for headache patients across different cultures of Western society. The HMSE and the HSLC proved valuable in clinical headache research. Since scores on HSLC and HMSE were associated with measures of physical and social functioning the HSLC and HMSE may be of particular interest for intervention studies aimed at enhancing level of functioning for headache patients.

Keywords Tension-type headache $\cdot$ Migraine .

Locus of control - Self-efficacy $\cdot$ SF-36 - Headache centre

\section{Introduction}

Psychological treatment strategies with relaxation, biofeedback, and/or cognitive therapy have been demonstrated to be effective in patients with migraine or tension-type headache [1-4]. However, not all patients seem to profit from psychological treatment and because of the variable response, interest has focused on the identification of predicting factors influencing treatment outcome. Several authors have proposed that psychological factors, e.g. locus of control (LOC) [5, 6], catastrophizing [7, 8], self-efficacy (SE) [9-11], and affective, mood and personality disorders [12-14], may influence both the pain intensity, frequency, headache impact and treatment outcome.

The definition of LOC is a patient's perception of factors influencing the pain, meaning to what extent the patient perceives that internal (own) or external (e.g. significant others or fate) factors are controlling the pain [15]. 
For pain patients, LOC has been shown to be related to pain coping style and treatment response and it has been reported that it is the specific pattern of LOC that is essential rather than just the scale with the highest score [15].

The definition of pain-related SE is a patient's confidence in his or hers abilities to influence the pain. Headache SE has been shown to be related to increased use of positive psychological coping strategies and reduction of anxiety [9] and to reduce the negative influence of stressful events on headache frequency [16]. A study of moderators and mediators of treatment outcome for persons with chronic tension-type headache showed, that, the treatment effect measured by headache activity for stress-management therapy alone and combined with antidepressant medication respectively were fully mediated by SE measured by Headache Management Self-Efficacy Scale (HMSE) [11]. The mediator effect of SE on outcome measured by headache disability was reduced to a third at most when a mood or anxiety disorder was present for both stress-management therapy alone and combined with antidepressant medication even though headache disability was significantly improved by both the treatments [11]. There was little or no mediator effect of SE for antidepressant medication alone [11]. Nash and Bach [17] found that higher SE for headache was associated with lower headache-related disability independent of headache frequency. A study by Rokicki et al. [18] indicated that the positive outcome of EMG biofeedback training could be related to changes in headache-related SE. The headache management SE scale is a four-item measure with each item matching one of four headache self-management behaviours and Bond et al. [10] found that a group of patients exposed to a 48 min videotape (content: headache education, effective use of headache medications, cognitive-behavioural stress management and stretchingbased muscle relaxation) had significantly higher headache management SE scores than a waiting list group. These results, thus, indicate the importance in behavioral headache treatment of measuring SE for both research and clinical purposes.

A study by Martin et al. [5] indicated that the HeadacheSpecific Locus of Control Scale (HSLC) accounted for variance in measures of depression, physical symptoms, disability, catastrophizing, medication use, and treatment preferences not accounted for by a measure of general LOC. These findings point to the need for headache-specific measures of LOC and SE. The HSLC [5] and HMSE [9] were selected since they to the best of our knowledge are the only headache-specific measures of the concepts of LOC and SE for which psychometric properties have been established.

Guillemin et al. [19] propose amongst others that the simple translation of a measure into another language is insufficient to obtain a valid version of the original version due to language and cultural differences. Bullinger et al. [20] also suggest evaluation of the psychometric properties of the translated version in order to secure cross-culturally comparable translations of surveys.

The aim of the present study was, therefore, to translate the HSLC and HMSE into Danish according to the proposed guidelines and investigate the reliability and validity of the Danish version by comparing findings with the Danish versions with the results from the original studies $[5,9]$. The final version of the Danish translation is presented and applied as a reference material for headache patients in a tertiary referral centre.

\section{Methods}

Patients referred to the Danish Headache Centre (DHC) were diagnosed according to the International Classification Headache Disorders, 2nd edition criteria [21] by experienced neurologists. Diagnoses were based on a 1-month headache diary, a structured interview, a clinical examination and para clinical tests when necessary. Patients who received a headache diagnosis were consecutively included. The DHC is the only national tertiary headache referral centre and offer multidisciplinary treatment strategies [22]. The period of inclusion ran from March to June 2003. HSLC, HMSE, symptom check list90-R (SCL-90 R), the medical outcomes study short-form questionnaire (SF-36), Beck's depression inventory (BDI) and Beck's anxiety inventory (BAI) were administered to the patients by a trained psychologist at their first visit at the DHC. Exclusion criteria were insufficient knowledge of Danish language or the patient lacking time.

The HSLC and HMSE were translated forward and backward using guidelines for cross-cultural adaptation provided by Beaton et al. [23].

Headache activity was based on the headache frequencies derived from the detailed diagnostic headache diaries [22]. Medication use was calculated in defined daily doses recommended by WHO [24] based on the information derived from the headache diaries regarding drugs and doses for three categories (over the counter analgesics, abortive migraine medication, and opiates).

Sick leave due to headache was based on patient's selfreported information prior to the first visit to the clinic.

The HSLC is a 33-item scale (5-point Likert's scale, $1=$ strongly disagree to $5=$ strongly agree). The scale includes three subscales measuring internal (own) and external [significant others (health-care professionals) and chance] LOC. In the original study, it was shown that HSLC predicts medication consumption, psychological consequences of headache episodes (e.g. depression and 
headache-related disability) and preference for treatment modality even when controlling for headache severity (frequency and intensity) in a sample of college students with recurrent headaches [5]. A replication study found similar psychometric characteristics for the HSLC subscales when applied to patients at a headache clinic [6].

The HMSE is a 25-item scale (7-point Likert's scale, $1=$ strongly disagree to $7=$ strongly agree). The scale measures the SE, i.e. "an individual's perception that they can engage in behaviors that will prevent or manage their recurrent headaches" [9]. The HMSE score predicts headache-related disability also when controlling for headache severity and HSLC scores [9].

The SCL-90-R is a 90-item self-report measure of psychological symptom patterns. Items are scored on a 5-point scale $(0=$ not at all to $4=$ extremely) according to how much discomfort the symptom caused during the last week. The original version consists of nine subscales and three summary indices: general symptomatic index (GSI), positive symptom distress level, and positive symptom total. Some cross-cultural validation studies have only found support for the GSI, since all subscales were highly correlated [25, 26]. A Danish version of the SCL-90-R has shown satisfying reliability and validity [27].

The SF-36 is a 36-item self-report measure of healthrelated quality of life. It consists of five scales measuring dysfunction [physical functioning (PF), role physical (RP), role emotional (RE), social functioning (SF) and bodily pain (BP)] and three scales measuring negative as well as positive aspects of health [mental health $(\mathrm{MH})$, vitality (VT) and general health (GH)]. Furthermore, it is possible to calculate two summary scales: the physical component summary for the four subscales (PF, RP, BP, and GH) primarily measuring physical health, and the mental component summary for the four subscales (VT, SF, RE, and $\mathrm{MH})$ primarily measuring mental health [28, 29]. On all scales, high scores reflect good health status. The scales differ with regard to number of items, reply possibilities and levels [30]. The Danish version of the SF-36 has demonstrated good internal consistency and homogeneity [31] and has been tested in a representative sample ( $n=4,080$ ) from the general Danish population [30].

The BDI and the BAI are 21-item self-report measures of depression and anxiety, respectively. The items of both measures are scored on a 4-point scale $(0=$ not at all to 3 = severely). The BDI measures intensity of depression. It is used worldwide and has been shown to reliably distinguish between depressed and non-depressed individuals [32]. The BAI is intended to asses the severity of symptoms of anxiety minimally shared with depression [33-35]. Enns et al. [36] concluded that BDI and BAI assess distinct symptoms of depression and anxiety in clinically depressed samples.
Statistics

Internal stability of the HSLC subscales and the HMSE were analysed using Chronbach's $\alpha$ coefficient. The psychometric properties of the HSLC and the HMSE were analysed using Spearman's rank correlation test with 0.05 and 0.01 as significance level (2-tailed). Possible differences across headache diagnoses (MIG, TTH, $\mathrm{MIG}+\mathrm{TTH}$, and $\mathrm{MOH}$ ) and gender were analysed using Mann-Whitney pair-wise tests with 0.05 as significance level (2-tailed). Possible differences between the scores of the sample of patients from a tertiary multidisciplinary headache centre and the scores of a representative sample from the Danish population on the eight subscales of SF-36 and GSI from SCL-90 were analysed using the Student's $t$ test with 0.01 as significance level (2-tailed).

\section{Results}

A total of 135 patients were included. The number of patients included in the calculations varies due to missing values. The mean age was 44 years $(\mathrm{SD}=13.7$, range $=$ 15-75) and $75 \%$ were women. The average patient had 20 headache days/month (2-30), consumed 30 standard doses of abortive medicine (analgesics and triptans)/month (0-220), and had five absence days due to headache/month (0-30). There were no gender differences amongst the clinical characteristics. Headache diagnoses and headache data for the different diagnostic groups and basic descriptive statistics for the study measures are shown in Tables 1 and 2, respectively. There were no significant differences in scores for HMSE and the three subscales of HSLC across gender and the larger groups of headache diagnoses (MIG, TTH, TTH + MIG, and MOH), except for the $\mathrm{MOH}$ patients having significantly $(P=0.045)$ higher scores on the internal LOC scale than patients with both TTH and MIG.

The included headache patients scored consistently and significantly $(P<0.005$ for all scales) lower than a representative sample from the general Danish population [30] on all SF-36 subscales (Fig. 1).

The level of psychological distress as measured by GSI was slightly, but significantly $(P<0.01)$ higher for the headache patients than for a representative sample from the general Danish population [37]. 27\% of our headache patients reported general distress above the national norm based cut-off score for clinical level of general distress compared with $17.5 \%$ in the general Danish population sample [37].

The HMSE and the subscales of HSLC showed good internal consistency (Cronbach's $\alpha$ ranging from 0.71 to 
Table 1 Headache characteristics in 129 consecutive patients (diagnoses, frequency, acute medication, and absence days due to headache)

\begin{tabular}{lcccr}
\hline Headache diagnosis & $N$ & Frequency & Medication use (DDD) & Absence of work \\
\hline Migraine only & 13 & $7(3-12)$ & $11(0-32)$ & $4(0-30)$ \\
TTH only & 17 & $28(9-30)$ & $22(0-60)$ & $9(0-30)$ \\
MIG and TTH & 43 & $14(2-30)$ & $14(0-47)$ & $4(0-30)$ \\
MOH & 35 & $23(4-30)$ & $62(0-220)$ & $4(0-30)$ \\
CPTH & 7 & $24(9-30)$ & $12(0-50)$ & $8(0-30)$ \\
CH & 5 & $16(3-30)$ & $12(0-35)$ & $3(0-14)$ \\
OTHER $^{\text {a }}$ & 9 & $24(7-30)$ & $44(0-135)$ & 8 \\
\hline
\end{tabular}

Data are presented as mean days/month (ranges in brackets)

TTH tension-type headache, $M I G$ migraine, MOH medication-overuse headache, CPTH chronic post-traumatic headache, $\mathrm{CH}$ cluster headache, $D D D$ defined daily doses

${ }^{\text {a }}$ Primarily headache attributed to non-vascular intracranial disorder and primary facial pain

Table 2 Descriptive statistics for test scores of the study measures (values from the original study of HMSE [9] in square brackets [ ])

HSLC Headache-Specific Locus of Control Scale, HMSE

Headache Management Self-

Efficacy Scale, $D D D$ defined daily doses, $B D I$ Beck's

depression inventory,

$B A I$ Beck's anxiety inventory,

GSI global severity index,

$P C S$ physical component score,

$P F$ physical function,

$G H$ general health,

MCS mental component score, PF

$S F$ social functioning $\quad \mathrm{GH}$

a The number of patients MCS

included in the calculations

varies due to missing values

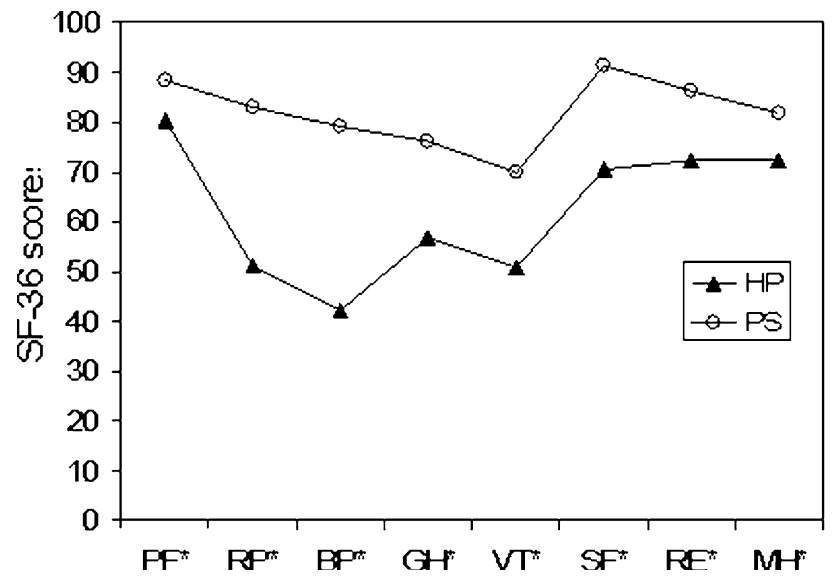

Fig. 1 SF-36 scores (mean) for headache patients (HP) $(n=135)$ and a Danish population sample (PS) $(n=4,080)$ [30]. $P F$ physical function, $R P$ role physical, $B P$ bodily pain, $G H$ general health, $V T$ vitality, $S F$ social functioning, $R E$ role emotional, $M H$ mental health; $* P<0.005$

\begin{tabular}{llll}
\hline Measure & Mean (SD) & Range & No. of patients \\
\hline HMSE & $91.7(25.1)[110.3(20.9)]$ & $32-154[48-163]$ & 133 \\
HSLC & & & \\
Internal & $34.2(9.9)[36.4(8.0)]$ & $11-55[11-52]$ & 135 \\
Chance & $35.0(8.9)[30.9(8.1)]$ & $15-68[13-51]$ & 133 \\
Professional & $28.4(7.0)[28.9(6.2)]$ & $11-46[11-47]$ & 133 \\
Headache frequency (days/month) & 20 & $2-30$ & \\
Medication use (DDD/month) & 30 & $0-220$ & 133 \\
BDI & $8.7(6.9)[9.1(7.0)]$ & $0-31[0-35]$ & 122 \\
BAI & $8.0(7.9)$ & $0-32$ & 135 \\
GSI (SCL-90-R) & $0.58(0.47)$ & $0.03-2.17$ & 135 \\
SF-36 & & & 135 \\
PCS & $40.4(9.4)$ & $12-58$ & 135 \\
PF & $80.3(21.0)$ & $0-100$ & 135 \\
GH & $56.7(21.8)$ & $0-100$ & 135 \\
MCS & $48.4(9.1)$ & $19-64$ & $13-100$ \\
SF & $70.5(23.9)$ &
\end{tabular}

0.88 ) and acceptable corrected item-total correlation (Table 3).

Construct validity of the HMSE and HSLC was assessed by examination of associations between the two scales and measures of health-related quality of life (SF-36) and psychological distress (BDI, BAI, and SCL90). Intercorrelations for the study measures are presented in Table 4.

High HMSE scores were found to be associated with high scores on internal LOC and low scores on chance LOC. High scores on HMSE had small, but significant correlations with low scores on GSI and BDI, and high scores on PF. The opposite correlations were found for headache frequency. There was no significant correlation between HMSE and headache frequency.

High scores on chance LOC were positively associated with low scores on SF independently of headache frequency. 
Table 3 Item correlations with scale scores and Cronbach's $\alpha$ for HSLC and HMSE items (values from original studies $[5,9]$ in brackets)

HSLC Headache-Specific Locus of Control Scale, HMSE Headache Management SelfEfficacy Scale

\begin{tabular}{lllll}
\hline Scale & $\begin{array}{l}\text { Item means } \\
\text { variance }\end{array}$ & \multicolumn{2}{l}{ Corrected item-total correlation } & \multirow{2}{*}{ Cronbach's $\alpha$} \\
& & & & \\
\hline HSLC & & & Range & \\
Health-care professional $(n=133)$ & 0.52 & 0.40 & $0.30-0.59$ & $0.75(0.88)$ \\
Internal $(n=135)$ & 0.13 & 0.59 & $0.35-0.74$ & $0.88(0.86)$ \\
Chance $(n=133)$ & 0.32 & 0.40 & $0.18-0.54$ & $0.71(0.84)$ \\
HMSE $(n=135)$ & 0.35 & $0.42(0.49)$ & $0.058-0.611(0.27-0.66)$ & $0.85(0.90)$ \\
\hline
\end{tabular}

Table 4 Correlation between HSLC and HMSE subscales and other measures (BDI, BAI, SCL-90 GSI), selected SF-36 subscales, and headache frequency $(\mathrm{HF})$

\begin{tabular}{|c|c|c|c|c|c|c|c|c|c|c|c|c|}
\hline \multirow[t]{2}{*}{ HMSE } & \multicolumn{3}{|c|}{ HSLC } & \multirow[t]{2}{*}{$\mathrm{HF}$} & \multirow[t]{2}{*}{ BDI } & \multirow[t]{2}{*}{ BAI } & \multirow[t]{2}{*}{ GSI } & \multicolumn{5}{|c|}{ SF-36 } \\
\hline & Int & Cha & Pro & & & & & PCS & PF & $\mathrm{GH}$ & MCS & SF \\
\hline
\end{tabular}

HMSE

HSLC

Int $0.43^{* *}$

Cha $-0.58 * *-0.15$

$\begin{array}{llll}\text { Pro } & 0.01 & 0.16 & 0.18 *\end{array}$

HF $\quad-0.16 \quad 0.02 \quad 0.35 * *-0.11$

BDI $-0.28 * * \quad 0.22 * \quad 0.27 * * \quad 0.19 * \quad 0.30 * *$

$\begin{array}{lllllll}\text { BAI } & -0.18 & 0.11 & 0.23 * & 0.26 * * & 0.08 & 0.60 * *\end{array}$

$\begin{array}{lllllll}\text { GSI }-0.22 * & 0.25 * * & 0.28 * * & 0.18 & 0.27 * * & 0.79 * * & 0.72 * *\end{array}$

SF-36

\begin{tabular}{|c|c|c|c|c|c|c|c|c|c|c|c|c|}
\hline PCS & 0.13 & -0.11 & $-0.19 *$ & -0.08 & $-0.25^{* *}$ & $-0.34 * *$ & -0.11 & $-0.70 * *$ & & & & \\
\hline PF & $0.18^{*}$ & -0.10 & $-0.18^{*}$ & -0.08 & $-0.22 *$ & $-0.50 * *$ & $-0.20 *$ & $-0.41 * *$ & $0.68 * *$ & & & \\
\hline GH & $0.21 *$ & -0.21 & $-0.29 * *$ & $-0.23 * *$ & $-0.39 * *$ & $-0.59 * *$ & $-0.42 * *$ & $-0.54 * *$ & $0.54 * *$ & $0.54 * *$ & & \\
\hline MCS & $0.20 *$ & -0.09 & $-0.29 * *$ & -0.09 & $-0.23^{*}$ & $-0.71 * *$ & $-0.60 * *$ & $-0.70 * *$ & 0.16 & $0.35 * *$ & $0.43 * *$ & \\
\hline SF & $0.18^{*}$ & -0.06 & $-0.20 *$ & -0.09 & -0.13 & $-0.47 * *$ & $-0.26 * *$ & $-0.37 * *$ & $0.55 * *$ & $0.46 * *$ & $0.38 * *$ & $0.51 * *$ \\
\hline
\end{tabular}

HSLC Headache-Specific Locus of Control Scale, HMSE Headache Management Self-Efficacy Scale, HF headache frequency, BDI Beck's depression inventory, BAI Beck's anxiety inventory, GSI global severity index, $P C S$ physical component score, $P F$ physical function, $G H$ general health, $M C S$ mental component score, $S F$ social functioning

$* P<0.05$

** $P<0.01$ (2-tailed)

\section{Discussion}

The present results suggest that the Danish versions of HMSE and HSLC are both reliable and valid measures of headache-specific SE and LOC with psychometric properties equal to those described in the original reports [5, 9] and a subsequent study [6]. The Danish versions of HMSE and HSLC have acceptable values for Cronbach's $\alpha$ and item-total correlations when tested in a sample of headache patients from a tertiary headache centre. We also identified significant correlations between HMSE and HSLC scores and measures of depression, anxiety, general psychopathology, and health-related quality of life corresponding with the original studies [5,9] even though different measures were employed. The results thus further support the validity of the concepts of headache-specific SE and LOC across different cultures of Western society.

We found a minor, but significant positive correlation between high headache-specific SE and good PF and low general psychological distress. Headache frequency did not correlate significantly with headache-specific SE, but had minor significant negative correlations with good physical function and low general psychological distress. Patients with high HMSE scores thus have better physical and SF and less symptoms of psychological distress. Similar results are reported in another study of SE and headache [16].

The reference material presented consists of patients consecutively referred to a tertiary referral headache centre and thus should be representative for patients seen in specialist headache centres. These psychological 
characteristics can be used as a reference material for the treatment of patients with rare headache diagnoses or headaches difficult to treat as well as baseline values for future treatment studies. The present reference material may, however, not be representative for the general headache population, as they are highly selected and characterised as having refractory or rare headache before they are referred.

Headache data consisted of frequencies only and more precise data (duration and intensity) may yield more information into the correlations between LOC and SE scores and headache activity.

The HMSE and the HSLC may help identifying patients with special needs for non-pharmacological treatment in a multidisciplinary headache centre, since headache-specific SE were found to correlate with general psychological distress, symptoms of depression, and physical function. The concepts of headache-specific SE and LOC may also be helpful in identifying possible mediators or moderators of non-pharmacological headache treatment [18]. The findings in the present study indicate that the Danish versions of HMSE and the HSLC are reliable and valid measures of the two concepts and we recommend the use of them in future studies of headache-specific LOC and SE.

Acknowledgments We thank Kenneth Holroyd for providing copies of the original versions of HSLC and HMSE and useful advice on the process, Ann Lyngberg and Adrian Tan for providing forward and backward translations of HMSE and HSLC, and last but not least Birte Albeck for administering of the tests.

Conflict of interest None.

\section{References}

1. Bogaards MC, ter Kuile MM (1994) Treatment of recurrent tension headache: a meta-analytic review. Clin J Pain 10:174-190

2. McCrory DC, Penzien DB, Hasselblad V, Gray RN (2001) Behavioral and physical treatments for tension-type and cervicogenic headache. Foundation for Chiropractic Education and Research, DesMoines

3. Campbell JK, Penzien DB, Wall E (2001) Evidence-based guidelines for migraine headache: behavioral and physical treatments. American Academy of Neurology, St. Paul

4. Sun-Edelstein C, Mauskop A (2008) Complementary and alternative approaches to the treatment of tension-type headache. Curr Pain Headache Rep 12(6):447-450

5. Martin NJ, Holroyd KA, Penzien DB (1990) The headache-specific locus of control scale: adaptation to recurrent headaches. Headache 30:729-734

6. VandeCreek L, O'Donnell F (1992) Psychometric characteristics of the headache-specific locus of control scale. Headache 32: 239-241

7. Turner JA, Jensen MP, Romano JM (2000) Do beliefs, coping, and catastrophizing independently predict functioning in patients with chronic pain? Pain 85:115-125
8. Hassinger HJ, Semenchuk EM, O'Brien WH (1999) Appraisal and coping responses to pain and stress in migraine headache sufferers. J Behav Med 22:327-340

9. French DJ, Holroyd KA, Pinell C, Malinoski PT, O'Donnell F, Hill KR (2000) Perceived self-efficacy and headache-related disability. Headache 40:647-656

10. Bond DS, Durrant L, Digre K, Baggaly S, Rubingh C (2004) Impact of self-help intervention on performance of headache management behaviors: a self-efficacy approach. Int J Allied Health Sci Pract 2. http://ijahsp.nova.edu/articles/Vol2num1/ dale_bond_phd.htm. Accessed 23 Jun 2009

11. Holroyd KA, Labus JS, Carlson B (2009) Moderation and mediation in the psychological and drug treatment of chronic tension-type headache: the role of disorder severity and psychiatric comorbidity. Pain 143(3):213-222

12. Penzien DB, Rains JC, Lipchik GL, Creer TL (2004) Behavioral interventions for tension-type headache: overview of current therapies and recommendation for a self-management model for chronic headache. Curr Pain Headache Rep 8:489-499

13. Mueller L (2000) Psychologic aspects of chronic headache. J Am Osteopath Assoc 100:S14-S21

14. Saper JR, Lake AE III (2002) Borderline personality disorder and the chronic headache patient: review and management recommendations. Headache 42:663-674

15. Seville JL, Robinson AB (2000) Locus of control in the patient with chronic pain. In: Gatchel RJ, Weisberg JN (eds) Personality characteristics of patients with pain. American Psychological Association, Washington, DC, pp 165-179

16. Marlowe N (1998) Self-efficacy moderates the impact of stressful events on headache. Headache 38:662-667

17. Nash JM, Bach AK (2000) Does self-efficacy account for levels of headache disability? Headache 40:422

18. Rokicki LA, Holroyd KA, France CR, Lipchik GL, France JL, Kvaal SA (1997) Change mechanisms associated with combined relaxation/EMG biofeedback training for chronic tension headache. Appl Psychophysiol Biofeedback 22:21-41

19. Guillemin F, Bombardier C, Beaton D (1993) Cross-cultural adaptation of health-related quality of life measures: literature review and proposed guidelines. J Clin Epidemiol 46:14171432

20. Bullinger M, Alonso J, Apolone G, Leplege A, Sullivan M, Wood-Dauphinee S, Gandek B, Wagner A, Aaronson N, Bech P, Fukuhara S, Kaasa S, Ware JE Jr (1998) Translating health status questionnaires and evaluating their quality: the IQOLA project approach. International quality of life assessment. J Clin Epidemiol 51:913-923

21. Subcommitee Headache Classification, of the International Headache Society (2004) The International classification of headache disorders: 2nd edn. Cephalalgia 24(Suppl 1):9-160

22. Zeeberg P, Olesen J, Jensen R (2005) Efficacy of multidisciplinary treatment in a tertiary referral headache centre. Cephalalgia 25:1159-1167

23. Beaton DE, Bombardier C, Guillemin F, Ferraz MB (2000) Guidelines for the process of cross-cultural adaptation of selfreport measures. Spine 25:3186-3191

24. WHO Collaborating Centre for Drug Statistics Methodology (2000) Guidelines for ATC classification and DDD assignment. WHO Colaborating Centre for Drug Statistics Methodology, Oslo

25. Holi MM, Sammallahti PR, Aalberg VA (1998) A Finnish validation study of the SCL-90. Acta Psychiatr Scand 97:42-46

26. Schmitz N, Hartkamp N, Kiuse J, Franke GH, Reister G, Tress W (2000) The symptom check-list-90-R (SCL-90-R): a German validation study. Qual Life Res 9:185-193

27. Olsen LR, Mortensen EL, Bech P (2004) The SCL-90 and SCL$90 \mathrm{R}$ versions validated by item response models in a Danish community sample. Acta Psychiatr Scand 110:225-229 
28. Ware JE, Kosinski M (2001) Interpreting SF-36 summary health measures: a response. Qual Life Res 10:405-413

29. Ware JE Jr, Kosinski M, Bayliss MS, McHorney CA, Rogers WH, Raczek A (1995) Comparison of methods for the scoring and statistical analysis of SF-36 health profile and summary measures: summary of results from the medical outcomes study. Med Care 33:AS264-AS279

30. Bjorner JB, Damsgaard MT, Watt T, Bech P, Rasmussen NK, Kristensen TS, Modvig J, Thunedborg K (1997) Dansk manual til SF-36 [Danish manual for the SF-36]. LIF, Copenhagen

31. Bjorner JB, Thunedborg K, Kristensen TS, Modvig J, Bech P (1998) The Danish SF-36 Health Survey: translation and preliminary validity studies. J Clin Epidemiol 51:991-999

32. Richter P, Werner J, Heerlein A, Kraus A, Sauer H (1998) On the validity of the Beck depression inventory: a review. Psychopathology 31:160-168
33. Beck AT, Epstein N, Brown G, Steer RA (1988) An inventory for measuring clinical anxiety: psychometric properties. J Consult Clin Psychol 56:893-897

34. Wilson K, de Beurs E, Palmer C, Chambless D (1999) Beck anxiety inventory. In: Maruish MA (ed) The use of psychological testing for treatment planning and outcomes assessment, 2nd edn. Lawrence Erlbaum Associates, Mahwah, pp 971-992

35. de Beurs E, Wilson KA, Chambless DL, Goldstein AJ, Feske U (1997) Convergent and divergent validity of the Beck anxiety inventory for patients with panic disorder and agoraphobia. Depress Anxiety 6:140-146

36. Enns MW, Cox BJ, Parker JD, Guertin JE (1998) Confirmatory factor analysis of the Beck anxiety and depression inventories in patients with major depression. J Affect Disord 47:195-200

37. Olsen LR, Mortensen EL, Bech P (2006) Mental distress in the Danish general population. Acta Psychiatr Scand 113(6):477-484 